\title{
Syphilis in Pregnant Women and Congenital Syphilis: Spatio-temporal Dynamics and Covariates in the Middle-income Country - São Paulo, Brazil
}

\author{
Joelma Alexandra Ruberti \\ University of São Paulo at School of Public Health \\ Mellina Yamamura \\ Federal University of São Carlos \\ Zilda Pereira da Silva \\ University of São Paulo at School of Public Health \\ Carmen Silvia Bruniera Domingues \\ São Paulo State Department of Health \\ Eliseu Alves Waldman \\ University of São Paulo at School of Public Health \\ Francisco Chiaravalloti Neto ( $\nabla$ franciscochiara@usp.br) \\ University of São Paulo at School of Public Health
}

\section{Research Article}

Keywords: syphilis in pregnant women (SPW), congenital syphilis, aids incidence

Posted Date: June 4th, 2021

DOI: https://doi.org/10.21203/rs.3.rs-567976/v1

License: (c) (i) This work is licensed under a Creative Commons Attribution 4.0 International License. Read Full License 


\section{Abstract}

We aimed to estimate the occurrence of syphilis in pregnant women (SPW) and congenital syphilis (CS) in the municipalities of the state of São Paulo (SP) and evaluate their relationship with socioeconomic, demographic, and health care variables. We developed an ecological study based on secondary data of SPW and CS with spatial and temporal components from 645 municipalities in SP and included data from 2007 to 2018. We modeled the data in a Bayesian context, considered spatial and temporal random effects, and used a binomial negative probability distribution. We found a continuous increase in the relative temporal risk of SPW, from 2007 to 2018, and CS, from 2007 to 2017 , when their incidences increased by 8.7 and 6.6 times, respectively. Moreover, this increase occurred in en bloc in practically all municipalities of SP. The increase in SPW was associated with teenage pregnancy, municipalities with a large number of inhabitants, and aids incidence. The increase in CS was associated with municipalities with a large number of inhabitants, incomplete antenatal care, inadequate technology to perform deliveries in the municipality, and aids incidence. Interventions to control these diseases are needed in almost all the municipalities of the SP.

\section{Introduction}

Syphilis is a disease whose etiological agent is Treponema pallidum. With the discovery of penicillin, the disease was expected to be eliminated. Nevertheless, the number of adults, pregnant women, and infected children has increased significantly ${ }^{1,2}$. Pregnant women with syphilis who do not receive the correct treatment may have fetal and neonatal deaths, preterm births, and babies with low birth weight. Live births (LB) can suffer from the clinical effects and consequences of T. pallidum infections.

In 2006, the Pan American Health Organization and other organizations agreed on the targets for the elimination of congenital syphilis (CS) ${ }^{3}$, stating that for it to be considered to be eliminated, the incidence rate must be $\leq 0.5$ cases for every 1,000 LB. Among the proposed objectives for the achievement of this goal are improvements in antenatal care and childbirth, qualifications of health professionals, and increases in the diagnoses and treatment of pregnant women and children. Additionally, a 95\% increase in HIV and syphilis testing in pregnant women and its integration into primary care were recommended. This would include the diagnosis and prevention of sexually transmitted infections with other health services. To assess the process of eliminating mother-to-child transmission and with a view to making decisions, a $95 \%$ increase in monitoring in participating countries has also been proposed ${ }^{4}$.

However, even with the implementation of these initiatives, CS and syphilis in pregnant women (SPW) have remained increasingly serious public health problems ${ }^{1,2}$. Korenromp et al. (2019) ${ }^{4}$ estimated that in 2016, the global prevalence of SPW was $0.69 \%$ and the global occurrence of CS was 661,000 cases. Accordingly, 355,000 cases with adverse outcomes were estimated, with 143,000 early fetal deaths and stillbirths, and 61,000 neonatal deaths. They also estimated the occurrence of 41,000 and 109,000 preterm or low-birth-weight births and children with clinical illnesses, respectively.

In Brazil, the detection rate of acquired syphilis (AS) has increased significantly in all age groups, especially in those aged 20-29 years. Between 2014 and 2018, its detection rate increased from 2.1 to 75.8 cases per 100,000 inhabitants. The SPW detection rates, between 2008 and 2018, evolved from 2.5 to 21.4 cases per 1,000 LB. The CS incidence rate increased from 1.9 cases per 1,000 LB in 2007 to 9.0 , in 2018. The state of São Paulo (SP) (Fig. 1) had similar rates. A comparison of the years 2007 and 2018 showed that the detection rate of SPW increased 11.6 times (from 1.8 to 20.9 cases per 1,000 LB) and incidence rate of CS increased 5.1 times (from 1.3 to 6.6 cases per 1,000 LB) ${ }^{5}$.

Important aspects in the study of syphilis, especially SPW and CS, are the evaluations of their spatial distributions and temporal evolutions, which are generally made using ecological designs. These evaluations allow the visualization of places with a greater probability of the occurrence, association of occurrence with the conditions of the territories with populations at risk, identification of risk areas that need prioritization, and assessment of the effectiveness of surveillance and control measures ${ }^{6}$. Furthermore, the most adequate design when we consider space and time are the models with space-time architecture. They allow these two dimensions to be considered simultaneously and the relationship with possible associated factors to be adjusted for the spatial and temporal autocorrelations of the response variables ${ }^{7,8}$.

However, few ecological studies with spatial or space-time designs for investigating SPW and CS have been conducted in Brazil. We conducted a search in PubMed, Web of Science, and Scopus for studies published from 2010 to 2020 and found only four studies conducted in Brazil on this theme ${ }^{9-12}$, highlighting the existence of a knowledge gap as none of the studies used space-time modeling, few focused lowincome countries, and none used SP as a study area. Thus, we aimed to estimate the occurrence of SPW and CS in the municipalities of SP and evaluate their relationships with socioeconomic, demographic, and health care variables.

\section{Results}


In SP, between 2007 and 2018, the Information System for Notifiable Diseases (SINAN) received notifications of 54,844 cases of SPW and 27,729 cases of CS. This corresponded, considering the 7,313,551 LB in the study period, to a global incidence rate of SPW of 7.50 cases per 1,000 LB-year and global incidence rate of CS of 3.79 cases per 1,000 LB-year. The expected values of the SPW and CS cases in each municipality and year were calculated from these rates. While the number of LB increased by only $1.8 \%$ from 2007 to 2018 , the number of notified cases of SPW and CS increased 10.8 and 4.1 times, respectively.

In the database (SPW and CS database and dictionary of variables in Supplementary Material), made up of 7,740 lines (12 years times 645 municipalities), there were null values in $52.0 \%$ of situations for SPW and in $64.6 \%$ for CS; hence, zero-inflated probability distributions were considered. The models with Poisson probability distribution, both non-inflated and zero-inflated models, showed an overdispersion and were disregarded. The results presented here refer to the modeling using zero-inflated and non-zero-inflated negative binomial probability distributions. Table 1 presents the deviance information criteria (DIC) for these models. For SPW, the intercept and random-effects model with the lowest DIC was the one with a zero-inflated negative binomial distribution. In both the probability distributions, the DIC values for the models with covariates were close. For CS, the DIC of the intercept and random-effects models were the same in both the probability distributions, and the non-zero inflated covariate model presented a lower DIC. From these results, we considered the zero-inflated negative binomial probability distribution for the SPW models and non-zero inflated distribution for the CS models.

We commenced with the intercept and random-effects models for both diseases, presenting the temporal relative risks (RR), spatial RR, and predicted RR, first, and then the results of the models with the inclusion of covariates. Figure 1 shows the temporal RR for SPW and CS, showing us that the SPW and CS incidences presented large increase during the study period. The temporal RR of SPW increased 8.7 times between 2007 and 2018 (from 0.33 to 3.19), presenting significant results between years. Between 2007 and 2017 , there was an increase in the temporal RR of CS (although it was slightly less pronounced), while there was a decrease in 2018. Between 2007 and 2017, the RR increased 6.6 times (0.35 to 2.67) and RR of 2018 (2.50), although not significant in relation to 2017, may have represented a reversal of the temporal trend of the increasing incidence of CS.

Figure 2 shows the spatial RR for SPW and CS for the municipalities and Regional Disease Surveillance (RDS) areas of SP considering the whole period and the global rates for both diseases. The spatial RR for SPW ranged from 0.33 (municipality of Pedregulho in RDS 13 ) to 3.61 (Santa Cruz do Rio Pardo in RDS 8). The spatial RR for CS ranged from 0.13 (Igarapava in RDS 13) to 4.57 (Presidente Alves in RDS 10). As shown in Figure 3A, the RDS with municipalities with higher risks of SPW were the RDS of São Paulo (\#1), Itapeva (\#27), Botucatu (\#11), Assis (\#8), Araraquara (\#6), and Presidente Prudente (\#16). In relation to CS, the following areas have municipalities with higher risks: RDS of São Paulo (\#1), Santos (\#20), Registro (\#18), Botucatu (\#11), Bauru (\#10), Assis (\#8), and Presidente Prudente (\#16).

Figures 3 and 4 present the predicted RR for SPW and CS for the years of the study period, municipalities, and the RDS of SP. We obtained these values through the intercept random-effects models considering the spatial and temporal autocorrelations and the interactions between them; therefore, the predicted RR were adjusted taking these into account. For comparison, the gross RR for SPW ranged from 0 to 20.84 , while the adjusted RR ranged from 0.05 to 6.26. Similarly, with CS, the gross RR ranged from 0 to 33.33 , and the adjusted RR ranged from 0.02 to 5.44 .

Figure 5, which presents the predicted RR for both diseases per year using box plots, indicates the dimension of the increase in the occurrence of SPW and CS. The predicted values of the RR for SPW and CS showed continuous growth over the years (Figure 2). Furthermore, this growth was widespread, occurring in all the municipalities of the SP. Until 2010 and 2009, the RR presented values below the unity for all the municipalities for SPW and CS, respectively. In 2015, approximately 50\% of the municipalities of SP presented an RR greater than or equal to unity. In 2017 and 2018, when CS and SPW peaked, the proportion of municipalities with RR over the unity was $71 \%$ (457 in 645 ) and $91 \%$ (584 in 645), respectively, for CS and SPW.

After presenting the results of the intercept plus random-effects models, we finalize the results with the inclusion of covariates in these models. The exploratory analyses of the covariates showed that the proportion of women between 18 and 24 years old with no education or an incomplete 1st cycle of elementary school, proportion of people between 15 and 19 years old who did not work or study, proportion of LB to adolescent mothers, proportion of mothers with fewer than four antenatal care consultations, aids incidence rate, number of inhabitants, and demographic density presented as outliers. To address this issue, we transformed the first five using the square root and the last two using the logarithm. The collinearity analysis with the variance inflation factor (VIF) revealed the necessity of removing the covariates of the average household income per capita, proportions of people with an income below half the minimum wage, and demographic density.

Table 2 presents the posterior mean relative risks and 95\% credible intervals for the covariates considered to be in the zero-inflated negative binomial model for SPW and the non-zero negative binomial model for CS. We considered a spatio-temporal architecture; therefore, the results for the covariates were adjusted for spatial and temporal autocorrelations and interactions between them; the items of significance are highlighted in yellow in Table 2. The model for SPW showed that the variation of 1 standard deviation (SD) of the square root of the 
proportion of LB to adolescent mothers, the logarithm of the number of inhabitants, and the square root of the aids incidence rate can result in an increase in the risk of the occurrence of this disease in $6 \%, 33 \%$, and $9 \%$, respectively. For CS, the variation of 1 SD of the proportion of pregnant women with inadequate antenatal care, the square root of the proportion of mothers with less than four antenatal care consultations, the logarithm of the number of inhabitants, and the aids incidence rate would result in an increase of $11 \%, 7 \%, 37 \%$, and $9 \%$, respectively, in the risk of CS. Municipality performed deliveries were considered a protective factor with a reduction of $21 \%$ in the risk of CS.

\section{Discussion}

This study showed a continuous increase in the temporal RR of SPW from 2007 to 2018, and CS, from 2007 to 2017 . Over these years, the incidence of SPW and CS increased 8.7 and 6.6 times, respectively. Moreover, this increase occurred in en bloc in approximately all the municipalities of SP. This occurred in the richest and most populated state of Brazil. SP represents more than $31 \%$ of the Brazilian gross domestic product, with approximately 46 million inhabitants, and is ranked the third most populous and cosmopolitan political unit in South America $^{13}$

In the analyses of the socioeconomic and demographic conditions, link to health services, and presence of a transmissible comorbidities such as aids, which also indirectly involved aspects related to programmatic vulnerability, we observed that the increase in SPW was influenced by teenage pregnancy, municipalities with a large number of inhabitants, and aids incidence. The conditions that influenced the increase of CS were municipalities with a large number of inhabitants, incomplete antenatal care, inadequate technology to perform deliveries in the municipality, and aids incidence.

Ecological studies set the stage for examining causal mechanisms and provide a better approach for exploring exposures that are easier to measure in groups of individuals than at the individual level ${ }^{14}$. An important aspect of ecological modeling is the consideration of whether the response variables are independent. This study, which uses space-time architecture, had both the possibility of spatial and temporal dependence. Here, this aspect can be considered through the use of Bayesian latent Gaussian models, so that the results obtained are adjusted for the spatial and temporal autocorrelations and the interactions between them ${ }^{7,8}$. Moreover, the malleability of these models for the use of negative binomial probability distribution inflated to zero proved to be the appropriate for analyzing the occurrence of SPW ${ }^{15}$.

Since space and time were part of the modeling, the Bayesian inference allowed us to obtain the RR describing the behavior of the diseases studied according to time (years), space (municipalities), and space-time (municipalities according to years). These last two results, related to the mapping of diseases and their risk, are invaluable tools, in view of the possibility of knowledge of areas with higher risks, in assisting in health decision-making, interpreting the implementation of existing actions, and intervening to reduce injuries through prevention programs ${ }^{6}$.

Our results showed a continuous increase in the incidence of SPW and CS. Since these two diseases display synergistic behavior, an increase in the second ${ }^{4}$ can lead to management difficulties in the first ${ }^{16}$. This demonstrated the importance of studies on this dynamic. An analysis of the global load of SPW and CS showed that Europe was the only region that presented a level close to elimination, despite estimates of declines in Southeast Asia. The Eastern Mediterranean and American regions showed the largest estimated increases in the prevalence of SPW ${ }^{4}$. A study in Mexico showed that only $53 \%$ of pregnant women underwent diagnostic tests ${ }^{17}$ and recently, a study conducted between 2012 and 2016 in the United States, demonstrated a significant increase in CS, from 8.4\% to 15.7 cases/100,000-LB ${ }^{18}$.

This incidence can be explained by the expansion of the coverage of tests to detect diseases and by the improvement in surveillance ${ }^{19}$. In Brazil, the availability of a rapid test for syphilis increased from 31,500 in 2011 to 3,156,410 in $2014^{20}$. In SP, this increase was greater: from 1,000 tests being available in 2011 to $1,314,700$ in $2017^{21}$. Such progress was also probably due to funds from the Unified Health System (Sistema Único de Saúde - SUS) in the "Rede Cegonha" program, whose aims are the improvement of care for women during pregnancy, childbirth and postpartum, for newborns and children up to 2 years old ${ }^{22}$, and investing in the mother and child binomial ${ }^{23}$. A study conducted in Brazil confirmed this tendency, showing that the increase in the capacity to identify asymptomatic cases of syphilis resulted in an increase in the notifications of acquired, gestational, and congenital syphilis ${ }^{20}$.

This increase was also influenced by the decreased use of condoms and loss of opportunity for treatment when penicillin was not administered in primary health care (PHC), as well as the global crisis supply shortages between 2014 and $2016^{9}$. This evidence was consistent with the results of this research, which showed a positive association between SPW and the proportion of live births to adolescent mothers, municipalities with a large number of inhabitants, and the incidence rate of aids. The evidence was also consistent with the results obtained for CS, which showed a positive association with the proportion of pregnant women with inadequate antenatal care, proportion of mothers with fewer than four antenatal care consultations, municipalities with a large number of inhabitants, municipalities that do not have support for delivery, and aids incidence rate. Some of the variables associated with CS were also associated with SPW, highlighting the finding of a previous study that the control of CS is directly linked to the management of syphilis in pregnant women during antenatal care 24 . 
A recent study ${ }^{4}$ pointed out that the increase in SPW and CS is closely related to the expressive increase in AS rates in the general population and people socially vulnerable to HIV and sexually transmitted infections (STI), such as men who have unprotected sex with men and those not covered by the search actions, such as those in the antenatal care protocol. Furthermore, authors ${ }^{12,24,25}$ demonstrated the importance of adequate antenatal care, syphilis screening, and the correct and timely treatment for the prevention of syphilis. For Kimball et al. $(2020){ }^{25}$, late seroconversion and the lack of early identification of cases were reflections of the increase in groups at risk and issues of social vulnerabilities such as the lack of adequate housing, low education, and lower access to information.

Other factors that influenced the spread of syphilis were related to the accelerated urbanization process seen in recent decades in Brazil. Consequently, there is increased social exclusion, generating segregated populations, difficulties in accessing urban services and infrastructure, greater exposure to violence, racial discrimination, and discrimination against women and children ${ }^{26}$. These situations, among others, affect the way a person falls ill and health needs of a population ${ }^{27}$. Nevertheless, in terms of health, larger populations can provide the impetus for a municipality to present a more comprehensive care network with greater investments due to greater demand ${ }^{28}$. However, municipalities with larger population sizes present greater disparities in their social determinants of health, including access to health services $^{27}$.

SP, with more than $20 \%$ of the Brazilian population, is a good example of this dichotomy. On the one hand, $32.5 \%$ of municipalities in SP have been classified as dynamic with high wealth and good levels of social indicators (longevity and education) while in contrast, $43.9 \%$ of its municipalities demonstrate inequalities, with high levels of wealth, but with unsatisfactory social indicators ${ }^{29}$. People are diverse in terms of culture and education, and they move indistinctly from capital to the interior or vice versa ${ }^{30}$.

This dichotomous context may also be indirectly linked to one of our research findings, due to the possible relationship of the increase in cases of CS in municipalities without adequate health technology to perform deliveries. Usually, larger municipalities also have more health technology available, and if PHC fails at some point, a population still has, indirectly, the hospital scope for acute cases. However, this factor denotes the great difficulties experienced in coordinating health care networks using PHCs, since strategic syphilis should not require hospital care being a condition that is treated nationally as a condition that is responsive to $\mathrm{PHC}^{31}$.

Neves et al. (2018) ${ }^{28}$ reported that in Brazil, for every ten basic health units, not even one is adequate for the care of chronic conditions. Nonetheless, in spite of the many obstacles, Brazilian PHCs contributed to the control of syphilis. In 2019, of the 12,650 cases of SPW registered in SP, 4,013 evolved to CS, approximately $72 \%$ of CS cases were avoided. Of those who progressed to CS, $28 \%$ had maternal reinfections close to delivery, even after adequate treatment, including a change of partner or untreated partner, and $14 \%$ of cases were diagnosed with syphilis only in the third trimester of pregnancy ${ }^{32}$.

Major challenges that needs to be overcome on a worldwide scale is the issues related to the incorrect treatment of syphilis during pregnancy and the lack of audits to identify flaws in the care process and the adequacy of the qualifications of health professionals. A study conducted in Brazil demonstrated these difficulties ${ }^{33}$ and another one conducted in Argentina pointed out that of the children identified with CS and born in hospitals (corresponding to $96 \%$ of the total CS cases), only $47 \%$ of their mothers completed the antenatal care serological screening, and only four were adequately treated ${ }^{34}$.

The lack of knowledge and the importance of health monitoring during pregnancy have been associated with populations of greater social vulnerability, with low schooling and non-white color/race. Women with low education have less access to information, which limits their knowledge of health care and, mainly, measures to prevent sexually transmitted diseases such as syphilis infection ${ }^{35,36}$. Equally, it is worth mentioning the existence of more vulnerable population groups in each municipality, especially with regard to adolescents, as evidenced by the results. A national study showed the association of so-called young people "nemnem" (NEET - Not in Education, Employment or Training) to the low parental education, lower income and rural areas ${ }^{37}$. A study in the United Kingdom indicated that young people were more likely to become unemployed, use drugs and alcohol, be involved in crimes, have poor health, and become pregnant in adolescence ${ }^{38}$.

Regarding the association of both situations of the disease (SPW and CS) with the aids incidence rate, HIV and syphilis affect populations with similar profiles in which co-infection is common. According to the literature, people infected with other STI, including syphilis, are three to five times more likely to acquire HIV39. Moreover, the prevalence of syphilis also occurs more frequently among HIV-positive pregnant women than among HIV-negative women, because pregnant women living with HIV may have a weaker immune systems than other pregnant women 40 .

Considering this study followed all the precepts of ecological design, it is necessary to indicate the need for research that can analyze, as robustly as this study, issues directly related to individual characteristics and that can contribute to the evaluation of the persistence of SPW and CS, as well as the facilitation of qualified audits to assess programmatic vulnerabilities involving their management, care and prevention.

Page 5/15 
Although Brazil has an extensive range of technical materials and well-established clinical protocols that regulate the management of SPW and CS, it is still necessary to standardize the therapeutic conduct of health professionals and identifying treatments with alternative drugs that can be used in periods of worldwide shortages of penicillin, among other factors.

This study had some limitations. Since these were secondary data, underreported cases may have coexisted. Another limitation was we were not able to consider variables indicative of programmatic vulnerability, such as the availability of penicillin in primary care and testing coverage for syphilis, due to the lack of free access to this type of data. This information have assisted in our discussion on aspects that may be related to the persistence of congenital syphilis. Furthermore, to avoid any misunderstanding regarding the interpretation of the research findings, due to ecological fallacy, inferences were always made for aggregates and not for individuals. We interpreted our results based on the characteristics of the regions and not individually in relation to pregnant women and LB.

The results obtained in this study may also be useful in the design of new studies for the evaluation of SPW and CS surveillance and control in SP, both from a spatial and temporal point of view. The en bloc increase in the occurrence of both injuries indicates that actions are required in almost all the municipalities of SP. However, the identification of municipalities and RDS at the greatest risk for these diseases also points to priority areas for the development and implementation of these actions. If, on the one hand, the growing tendency of SPW points to difficulties in its control, the reversal of the temporal tendency of CS, even if not statistically significant, can be an indication of the resoluteness of the actions that have been developed.

\section{Methods}

\section{Type, period, area and study population}

This ecological study was based on secondary data with spatial and temporal components. The study area comprised 645 municipalities in SP (Fig. 6) and the study period, was from 2007 to 2018. SP occupies an area of $248,220 \mathrm{~km} 2$ and in 2018 it had a population of 43,993,189 inhabitants. It is divided into 28 Regional Disease Surveillance areas (RDSs). Based on the 2010 population census, the human development index for SP was 0.783 . Between 2007 and 2018, infant mortality rates and the proportions of pregnant women who had more than six consultations evolved from 13.1 to 10.8 deaths aged under one year per 1,000 LB and from $74.8-79.7 \%$, respectively ${ }^{41}$. The study population included cases of SPW and CS in LB living in SP for which the SINAN received notifications, from 2007 to 2018.

\section{Source of data and variables}

The year and the municipality of the notified cases of SPW and CS constituted the two response variables in this study. We obtained this data from the Epidemiological Bulletin of $\mathrm{SP}^{5}$, which is prepared and disseminated periodically by the STI and HIV/Aids Program of SP. Information on the year and municipality of LBs, was obtained from the Live Birth Information System ${ }^{41}$.

Possible factors associated with the occurrence of the conditions studied were socioeconomic, demographic, and health care variables. We considered the proxies for the socioeconomic and demographic conditions of the following variables, obtained for each of the municipalities, to be: proportion of women of childbearing age ( 15 to 49 years); proportion of women between 18 and 24 years old with no education or with an incomplete 1st cycle of elementary school; average household income per capita in Reais (the Brazilian currency); Gini index; proportions of people with an income below a quarter and half of the minimum wage; proportion of people between 15 and 19 years old who did not work or study; proportion of people between 15 and 19 years old who did not attend school; number of inhabitants; and demographic density. This information was obtained from the 2010 Population Census database provided by the Brazilian Institute of Geography and Statistics ${ }^{42}$. In this group, we also considered the presence of prisons in the municipality. It was a categorical variable, with a unique value (yes or no) for each municipality during the entire study period.

We considered the proxies for the factors related to health care to be: the proportion of pregnant women with inadequate antenatal care, the proportion of LB to adolescent mothers (aged 19 years or less), the municipality that performed deliveries (categorical: yes or no), and the proportion of mothers with less than four antenatal care consultations. This information was obtained from the Live Birth Information System ${ }^{41}$. For the construction of the variable proportion of pregnant women with inadequate antenatal care we considered information for the year 2014, which was the median year period and the first year for which information was available. In the calculation, the pregnant women with inadequate antenatal care (women who began antenatal care after the first trimester of pregnancy and those who, although they had started antenatal care until the third month of gestation, they had less than three consultations) was as the numerator and, the number of LBs the denominator. The variable proportion of LB to adolescent mothers, municipality that performed deliveries, and proportion of mothers with less than four antenatal care consultations were obtained for each year of the study period and for each municipality. 
We also considered, as part of the conditions related to healthcare, the aids incidence rate. This was calculated by dividing the notified aids cases by the population (cases per 100,000 inhabitants) for each municipality and year of the study period. The data of notified aids cases were obtained from the Epidemiological Bulletin of $\mathrm{SP}^{5}$.

Based on the information presented, a database was constructed containing the numbers of cases of SPW and CS in each municipality and for each year and the expected cases of the two diseases by municipality and year. These were calculated from the global rates of detection of SPW and the incidence of CS (per thousand LB-years) for the entire study period. The expected values of SPW and CS were obtained for each year and municipality by multiplying the global rates by the number of LB and dividing the result by 1,000 . These values represented the expected number of SPW and CS cases in a specified municipality, in a given year, if the city had the same rates as the entire study area. To this database, socioeconomic, demographic, and health care variables (presented above) were added and were considered as covariates. This database is available in the Supplementary Material, named SPW and CS databases.

\section{Data analysis}

An exploratory analysis was conducted to assess the existence of outliers, quantities of zeros in the response variables, identification of collinearity between the covariates, and evaluation of the relationships between the two outcomes and each of the covariates. The collinearity analysis was performed by calculating VIF. Covariates with VIF > 3 were considered to be collinear with one or more of the others and were not included in the modeling ${ }^{43}$.

The modeling took into account a space-time architecture; therefore, random spatial and temporal random effects and those relative to the interaction between space and time, were considered. The spatial random effects were modeled according to the model proposed by Besag et al. (1991) ${ }^{44}$ and called the Besag-York-Molié (BYM). It consisted of two types of random effects: a structured spatial random effect that represented local spatial dependence between municipalities, and an unstructured spatial random effect that represented global spatial dependence ${ }^{44}$. Here, the BYM2 model was used according to the modifications proposed by Riebler et al. $(2016)^{45}$. The contiguity was considered as a criterion to establish the neighborhood matrix between municipalities. The time dependence was modeled considering an unstructured random-effects and a structured one, which was named the random walk type 1 (RW1). The interaction between space and time was modeled by two unstructured random effects, one in space and another in time ${ }^{7}$.

We ran the models using the integrated nested Laplace approximation (INLA) approach in a Bayesian context ${ }^{15}$. Initially, for both SPW and CS models, the Poisson probability distributions, uninflated, and inflated zeros were considered. Since these models showed an overdispersion (variances greater than the respective averages), we used negative binomial distributions, non-inflated and inflated zeros, in the modeling. The expected cases of SPW and CS were considered as offsets in the modeling; therefore, the results obtained were interpreted on a natural scale as RR to the global rates of detection of SPW and incidence of CS. Initially, only the intercept and random effects models were examined, and

later, the models with covariates were added. In the modeling, these were first centered by subtracting the respective averages and then scaled by dividing the values obtained by the respective SDs.

The priors adopted for the random effects were those recommended by Simpson et al. $(2017)^{46}$, that is, priors with a penalized complexity. Non-informative priors were adopted for the fixed effects model. The DIC was used as a measure of the degree of adjustment of the models, so that the lower the DIC, the better was the model adjustment ${ }^{7}$. We conducted the analysis using the R program version 3.6 .1 (R Core Team 2019) and in the packages R-INLA ${ }^{15}$, INLAOutputs ${ }^{47}$, devtools ${ }^{48}$, tidyverse $^{49}$, sf $^{50}$, spdep $^{51}$ and lattice ${ }^{52}$.

\section{Declarations}

Ethical considerations

All information used in this study was obtained from sources with universal public access, this study was not submitted to a research ethics committee for approval.

\section{Contributions}

F.C.N. and J.A.R.M.: conceptualization, methodology, supervision, project administration. M.Y.; Z.P.S.; C.S.B.D.; E.A.W.: data curation, formal analysis, validation. P.P.: investigation, visualization. All authors drafted the manuscript, read and approved the final manuscript.

\section{References}

1. Stam, LV. Syphilis: re-emergence of an old foe. Microbial Cel/ 3, 9 https://doi.org/10.15698/mic2016.09.523 (2016). 
2. Milanez, H. Syphilis in Pregnancy and Congenital Syphilis: Why Can We not yet Face This Problem? Rev Bras Ginecol Obstet 38, 9 https://doi.org/10.1055/s-0036-1593603 (2016).

3. Pan American Health Organization. Elimination of Mother-to-Child Transmission of HIV and Syphilis in the Americas. https://iris.paho.org/bitstream/handle/10665.2/34072/9789275119556-eng.pdf(PAHO, 2014).

4. Korenromp, EL. et al. Global burden of maternal and congenital syphilis and associated adverse birth outcomes. Estimates for 2016 and progress since 2012. PLoS ONE14, 2, e0211720. https://doi.org/10.1371/journal.pone.0211720 (2019).

5. Secretaria de Estado da Saúde de São Paulo. Boletim Epidemiológico de HIV-AIDS-IST. Programa Estadual de IST/Aids de São Paulo 36, 1. https://www.saude.sp.gov.br/resources/crt/vig.epidemiologica/boletim-epidemiologico-crt/boletim_2019.pdf (2019).

6. Piel, FB. et al. Software application profile: the Rapid Inquiry Facility 4.0: an open access tool for environmental public health tracking. Int J Epidemio/49, i38-i48. https://doi.org/10.1093/ije/dyz094 (2020).

7. Blangiardo, M, Cameletti, M. Spatial and Spatio-Temporal Bayesian Models with R-INLA John Wiley \& Sons, Oxford (2015).

8. Zuur, AF, Elena, NI, Anatoly, AS. Beginner's Guide to Spatial, Temporal, and Spatial-Temporal Ecological Data Analysis with R-INLA Volume I: Using GLM and GLMM. Highland Statistics Ltd. Newburgh United Kingdom (2017).

9. Oliveira, LR, Santos, ES, Souto, FJD. Syphilis in pregnant women and congenital syphilis: spatial pattern and relationship with social determinants of health in Mato Grosso. Rev Soc Bras Med Trop 53, e20200316. https://doi.org/10.1590/0037-8682-0316-2020 (2020).

10. Soares, KKS, et al. Análise espacial da sífilis em gestantes e sífilis congênita no estado do Espírito Santo, 2011-2018. Epidemiol. Serv. Saúde29, 1, e2018193, 2020. https://doi.org/10.5123/s1679-49742020000100018 (2020).

11. Souza, CDF, et al. Spatiotemporal clustering, social vulnerability and risk of congenital syphilis in northeast Brazil: an ecological study. Transactions of The Royal Society of Tropical Medicine and Hygiene114, 9, 657-665. https://doi.org/10.1093/trstmh/traa034 (2020).

12. Texeira, LO, Belarmino, V, Gonçalves, AV, Mendoza-Sassi, RA. Tendência temporal e distribuição espacial da sífilis congênita no estado do Rio Grande do Sul entre 2001 e 2012. Ciência \& Saúde Coletiva23, 8, 2587-2597. https://doi.org/10.1590/1413-81232018238.25422016 (2018).

13. Governo do Estado de São Paulo. São Paulo: potência em história, economia, cultura e turismo. https://www.saopaulo.sp.gov.br/conhecasp/ (2021).

14. Lokar, K, Zagar, T, Zadnik, V. Estimation of the Ecological Fallacy in the Geographical Analysis of the Association of Socio-Economic Deprivation and Cancer Incidence. Int J Environ Res Public Health16, 3, 296. https://doi.org/10.3390/ijerph16030296 (2019).

15. Rue, H, Martino, S, Chopin, N. Approximate Bayesian inference for latent Gaussian models by using integrated nested Laplace approximations. Journal of the Royal Statistical Society 71, 319-392. https://doi.org/10.1111/j.1467-9868.2008.00700.x (2009).

16. Nonato, SM, Melo, APS, Guimarães, MDC. Sífilis na gestação e fatores associados à sífilis congênita em Belo Horizonte-MG, $2010-2013$. Epidemiologia e Serviços de Saúde24, 4, 681-694. https://doi.org/10.5123/S1679-49742015000400010 (2015).

17. Reyna-Figueroa, J, et al. Congenital syphilis, a reemergent disease in Mexico: its epidemiology during the last 2 decades. Sex Transm Dis38,(9), 798-801. https://doi.org/10.1097/OLQ.0b013e31821898ca (2011).

18. Kidd, S, Bowe, VB, Torrone, EA, Bolan, G. Use of National Syphilis Surveillance Data to Develop a Congenital Syphilis Prevention Cascade and Estimate the Number of Potential Congenital Syphilis Cases Averted. Sex Transm Dis45, S23-S28. https://doi.org/10.1097/OLQ.0000000000000838 (2018).

19. Oliveira, CM, Cruz, MM. Sistema de Vigilância em Saúde no Brasil: avanços e desafios. Saúde debate39, 104, $255-267$. https://doi.org/10.1590/0103-110420151040385 (2015).

20. Figueiredo, DCMM, et al. Relação entre oferta de diagnóstico e tratamento da sífilis na atenção básica sobre a incidência de sífilis gestacional e congênita. Cadernos de Saúde Pública36, 3. https://doi.org/10.1590/0102-311X00074519 (2020).

21. Brasil. Ministério da Saúde. Boletim Epidemiológico de Sífilis49, 45. http://www.aids.gov.br/pt-br/pub/2018/boletim-epidemiologico-desifilis-2018 (2018).

22. Almeida, JM, Nader, RGM, Mallet, ACT. Intestinal microbiota in the first thousand days of life and its relation to dysbiosis. Research, Society and Development10, .2, e35910212687. https://doi.org/10.33448/rsd-v10i2.12687 (2021).

23. Souza, JM et al. Mother-to-child transmission and gestational syphilis: Spatialtemporal epidemiology and demographics in a Brazilian region. PLoS Negl Trop Dis13, (2), e0007122. https://doi.org/10.1371/journal.pntd.0007122 (2019).

24. Kimball, A et al. Missed opportunities for prevention of congenital syphilis - United States, 2018. Morbidity and Mortality Weekly Report 69, (22), 661-665. https://www.cdc.gov/mmwr/volumes/69/wr/mm6922a1.htm (2020).

25. Vianna, PVC, Helbusto, NB, Barja, PR, Medeiros, APP. Sífilis congênita em um município paulista de grande porte: um olhar a partir da vulnerabilidade socioespacial. Rev. Intellectus48. http://www.inicepg.univap.br/cd/INIC_2016/anais/arquivos/0670_0443_01.pdf (2018). 
26. World Health Organization. A conceptual framework for action on the social determinants of health. https://www.who.int/sdhconference/resources/ConceptualframeworkforactiononSDH_eng.pdf (WHO, 2010).

27. Neves, RG, et al. Estrutura das unidades básicas de saúde para atenção às pessoas com diabetes: Ciclos I e II do Programa Nacional de Melhoria do Acesso e da Qualidade. Cadernos de Saúde Pública34, 4, e00072317. https://doi.org/10.1590/0102-311X00072317 (2018).

28. Fundação Sistema Estadual de Análises de Dados. Portal de Estatísticas do Estado de São Paulo. O Estado dos municípios $2010-2012$ Índice Paulista de Responsabilidade Social.

http://www.saude.sp.gov.br/resources/crt/vig.epidemiologica/dadosepidemiologicos/planilhasgsc_dadosbol2015_sinanate30.06.15.pdf (2016)

29. Maria, PFD, Baeninger, R. Imigração em São Paulo: perfis segundo pobreza e ocupação no século XXI. Revista Geografias 41-62. https://periodicos.ufmg.br/index.php/geografias/article/view/13446 (2017).

30. Brasil. Ministério da Saúde. Portaria № 221, de 17 de Abril de 2008. Diário Oficial. http://dtr2001.saude.gov.br/sas/PORTARIAS/Port2008/PT-221.htm (2008).

31. Brasil. Ministério da Saúde. Boletim Epidemiológico de Síflis. http://www.aids.gov.br/pt-br/pub/2019/boletim-epidemiologico-sifilis-2019 (2019).

32. Benzaken, AS. et al. Adequação de atendimento pré-natal, diagnóstico e tratamento da síflis gestacional: um estudo com dados abertos de capitais brasileiras. Cad. Saúde Pública, 36, 1, e00057219. http://dx.doi.org/10.1590/0102-311x00057219 (2019).

33. Garcia, LN, et al. Congenital syphilis in Argentina: Experience in a pediatric hospital. PLoS Negl Trop Dis15, (1), e0009010. https://doi.org/10.1371/journal.pntd.0009010 (2021).

34. Cardoso, ARP, et al. Análise dos casos de sífilis gestacional e congênita nos anos de 2008 a 2010 em Fortaleza, Ceará, Brasil. Ciênc saúde colet 23, 2, 563-574. https://doi.org/10.1590/1413-81232018232.01772016 (2018).

35. Heringer, ALS, et al. Inequalities in congenital syphilis trends in the city of Niterói, Brazil, 2007-2016. Rev Panam Salud Publica, 44 , e3. https://doi.org/10.26633/RPSP.2020.8 (2020).

36. Tillman, E, Comin, F. Os determinantes da decisão entre estudo e trabalho dos jovens no Brasil e a geração nem-nem. Pesquisa e planejamento econômico46, 2. http://repositorio.ipea.gov.br/handle/11058/7290 (2016).

37. Russell, L, Simmons, R, Thompson, R. Conceptualising the lives of NEET young people: structuration theory and 'disengagement'. Education, Knowledge and Economy5, 3, 89-106. http://dx.doi.org/10.1080/17496896.2012.662010 (2011).

38. Solomon, $\mathrm{H}$, et al. Prevalence and correlates of active syphilis and HIV co-Infection among sexually active persons aged 15-59 years in Zambia: Results from the Zambia Population-based HIV Impact Assessment (ZAMPHIA) 2016. PLoS ONE15, (7), e0236501. https://doi.org/10.1371/journal.pone.0236501 (2020).

39. Kengne-Nde, C, et al. Highlighting a population-based re-emergence of Syphilis infection and assessing associated risk factors among pregnant women in Cameroon: Evidence from the 2009, 2012 and 2017 national sentinel surveillance surveys of HIV and syphilis. PLoS ONE 15, (11), e0241999. https://doi.org/10.1371/journal.pone.0241999 (2020).

40. Brasil, Ministério da Saúde. Banco de dados do Sistema Único de Saúde - DATASUS. Informações de Saúde (TABNET). http://www2.datasus.gov.br/DATASUS/ (2021).

41. Brasil, Instituto Brasileiro de Geografia e Estatística. IBGE Cidades. https://cidades.ibge.gov.br/brasil/sp/sao-paulo/panorama (2020).

42. Zuur, AF, leno, EN, Elphick, CS. A protocol for data exploration to avoid common statistical problems. Methods Ecol Evol 1, 3-14. https://doi.org/10.1111/j.2041-210X.2009.00001.x (2010).

43. Besag, J, York, J, Mollie, A. Bayesian image restoration, with two applications in spatial statistics. Ann Inst Stat Math43, 1-20. https://doi.org/10.1007/BF00116466 (1991).

44. Riebler, A, Sørbye, SH, Simpson, D, Rue, H. An intuitive Bayesian spatial model for disease mapping that accounts for scaling. Stat Methods Med Res 25, (4), 1145-65. https://doi.org/10.1177/0962280216660421 (2016).

45. Simpson, D, et al. Penalising model componente complexity: a principled, pratical approach to constructing priors. Statistical Science32, 1, 1-28. (2017).

46. Baquero, OS. INLAOutputs: process selected outputs. 'INLA' Package. http://oswaldosantos.github.io/INLAOutputs (2018).

47. Wickham, H, Hester, J, Chang. devtools: Tools to Make Developing R Packages Easier. R package version 2.1.0. https://CRAN.Rproject.org/package=devtools (2019).

48. Wickham, H, et al. Welcome to the Tidyverse. Journal of Open Source Software4, 1686. https://doi.org/10.21105/joss.01686 (2019).

49. Pebesma, E. Simple Features for R: Standardized Support for Spatial Vector Data. The R Journa/10, (1), 439-446. https://doi.org/10.32614/RJ-2018-009 (2018). 
50. Bivand, RS, Wong, DWS. Comparing implementations of global and local indicators of spatial association. TEST27, (3), 716-748. https://doi.org/10.1007/s11749-018-0599-x (2018).

51. Sarkar, D. Lattice: Multivariate Data Visualization with R. Springer, New York. ISBN 978-0-387-75968-5 (2008).

\section{Figures}

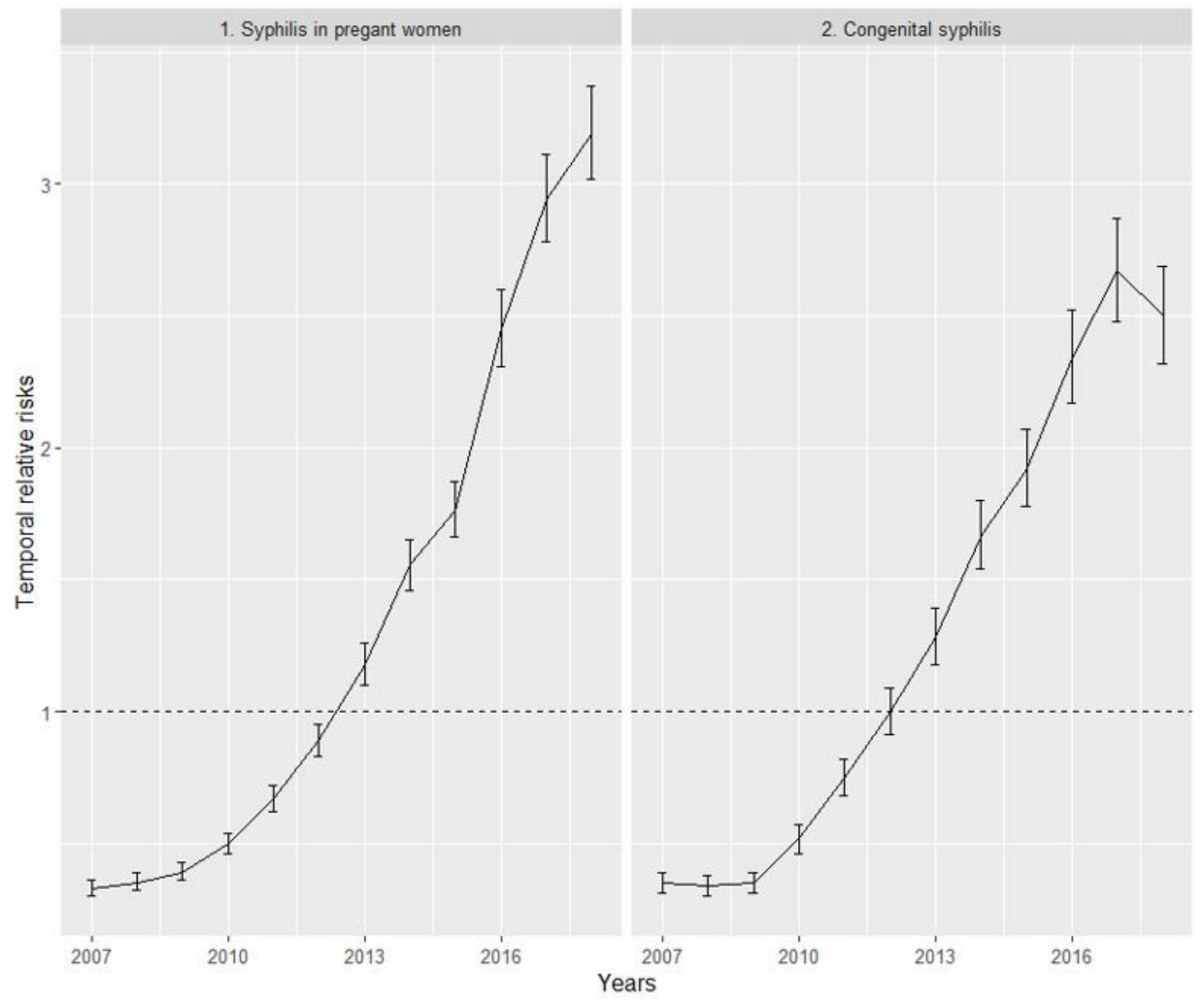

\section{Figure 1}

Posterior mean temporal relative risks and $95 \%$ credibility intervals for the combined unstructured and structured temporal random effect for the occurrence of syphilis in pregnant women and congenital syphilis per year, 2007 to 2018, state of São Paulo. 

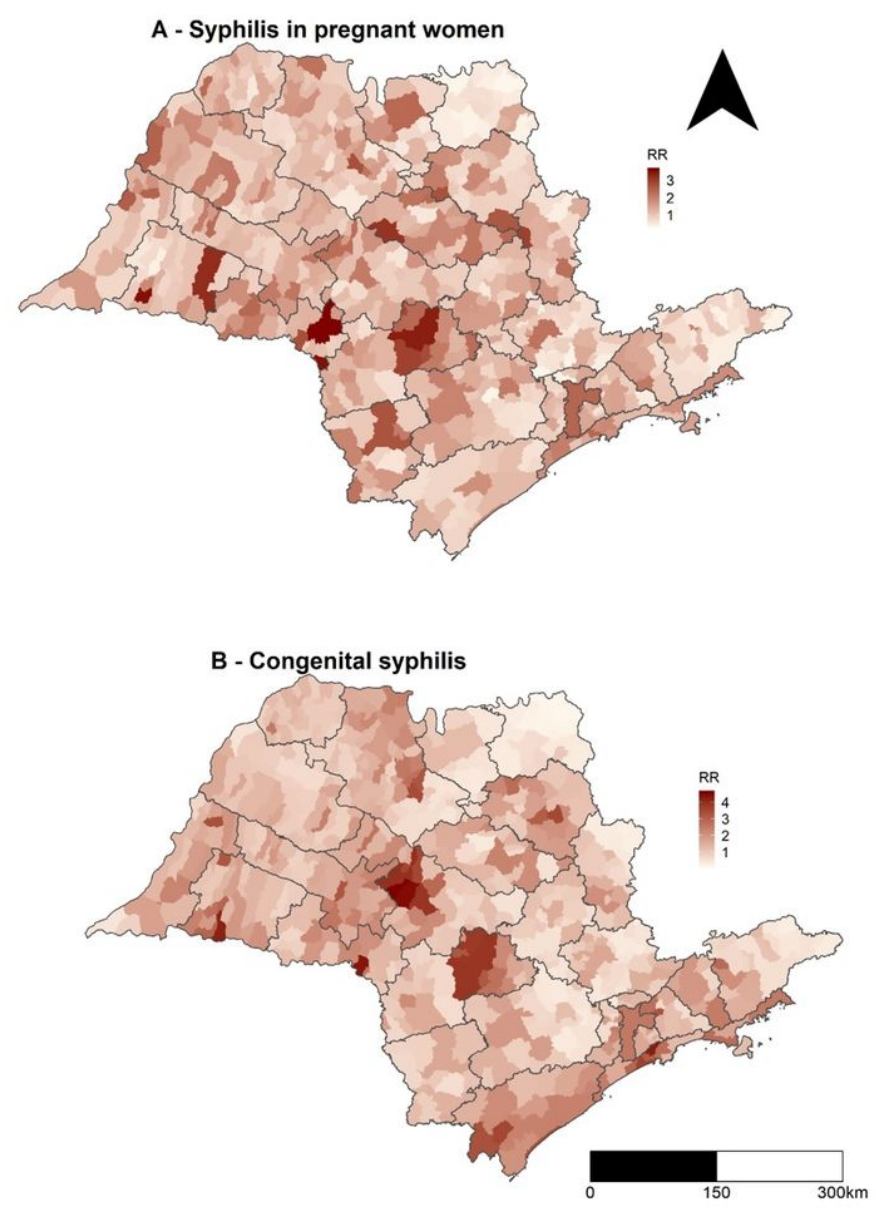

\section{Figure 2}

Posterior mean spatial relative risks for the combined unstructured and structured spatial random effects for the occurrence of syphilis in pregnant women (A) and congenital syphilis (B) per municipality and Regional Disease Surveillance, 2007 to 2018, state of São Paulo. Note: The designations employed and the presentation of the material on this map do not imply the expression of any opinion whatsoever on the part of Research Square concerning the legal status of any country, territory, city or area or of its authorities, or concerning the delimitation of its frontiers or boundaries. This map has been provided by the authors. 

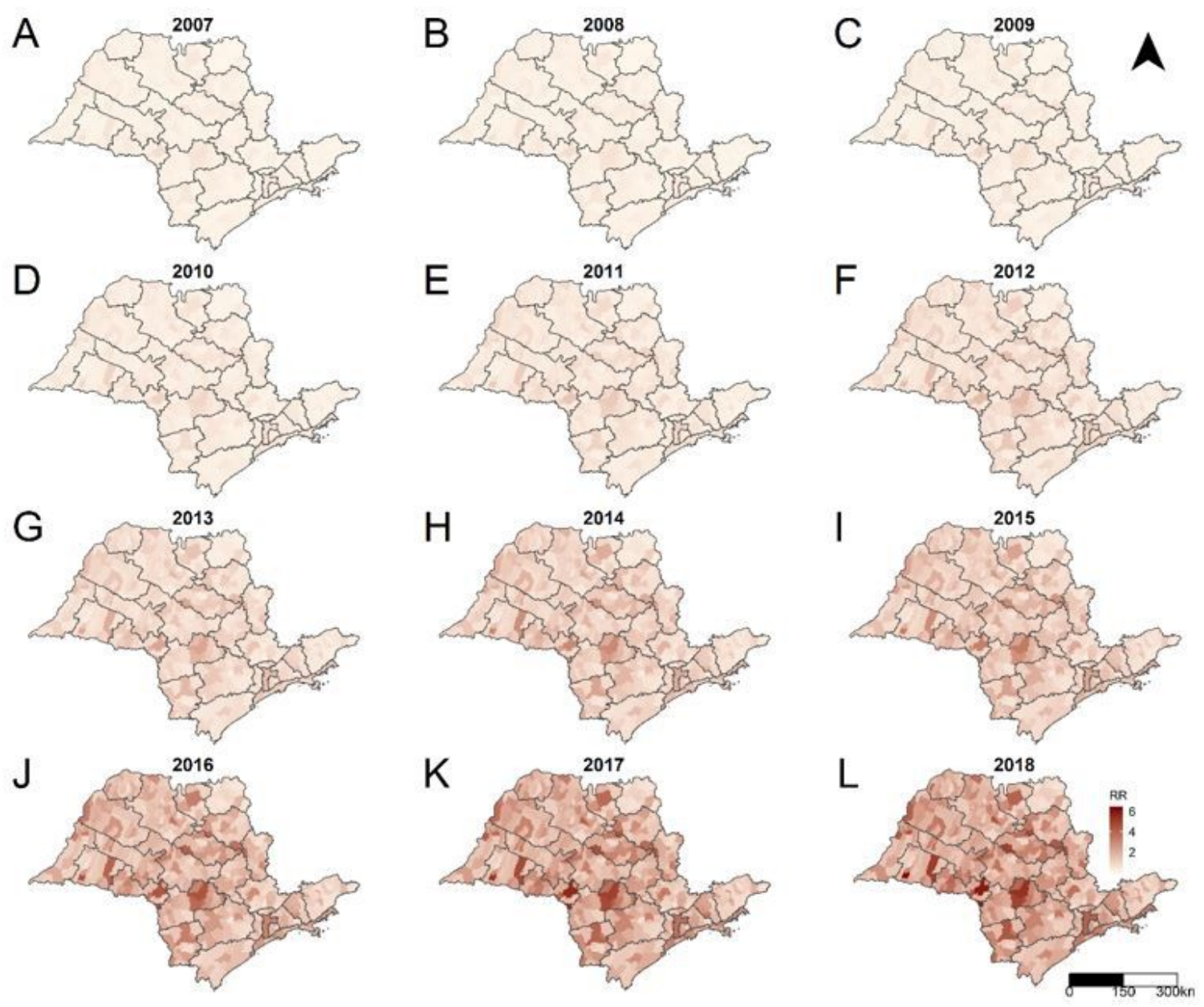

\section{Figure 3}

Posterior mean relative risks for syphilis in pregnant women per year, municipalities and Regional Disease Surveillance, state of São Paulo, 2007 (A) to 2018 (L). Note: The designations employed and the presentation of the material on this map do not imply the expression of any opinion whatsoever on the part of Research Square concerning the legal status of any country, territory, city or area or of its authorities, or concerning the delimitation of its frontiers or boundaries. This map has been provided by the authors. 

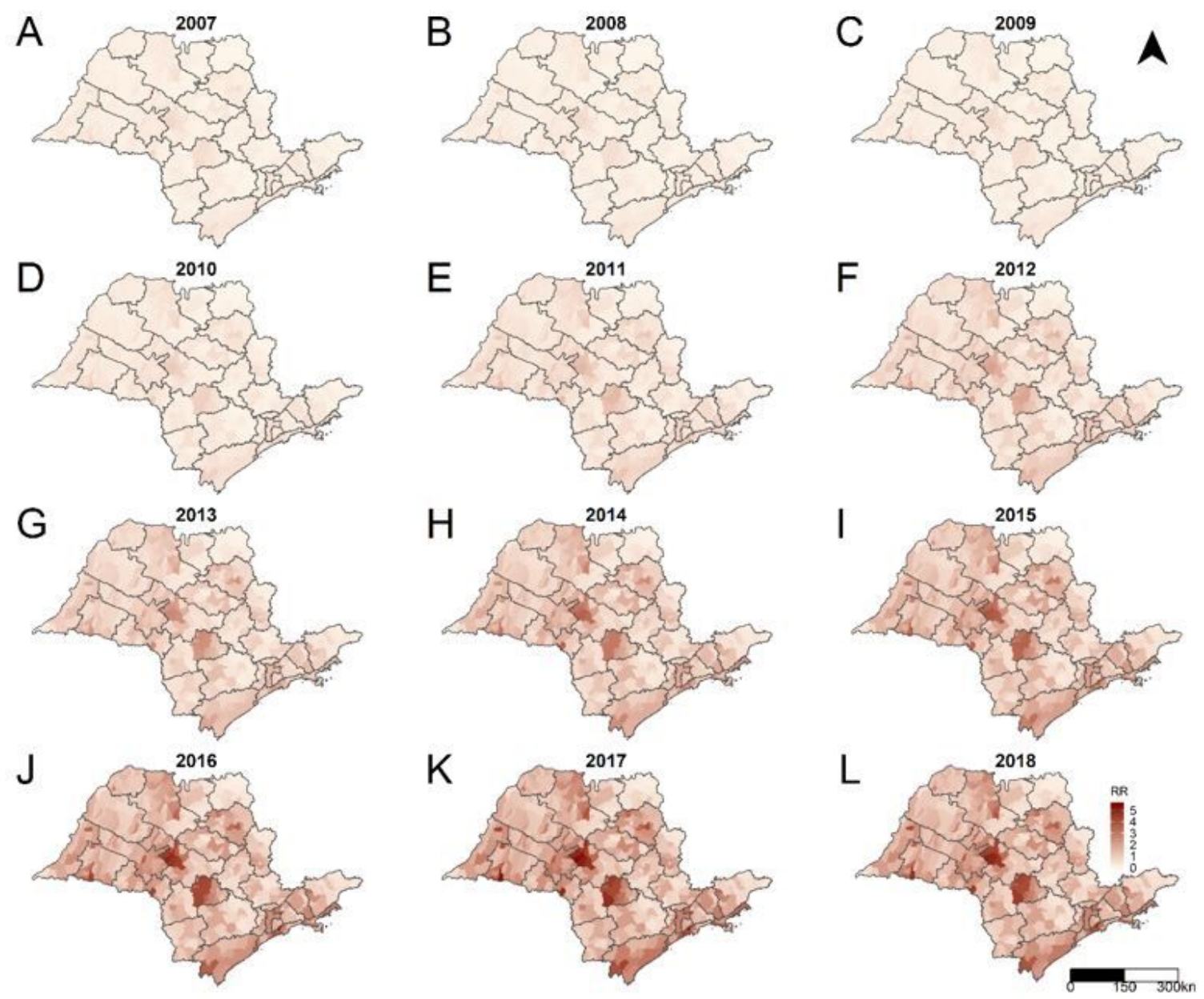

Figure 4

Posterior mean relative risks for congenital syphilis per year, municipalities and Regional Disease Surveillance, state of São Paulo, 2007 (A) to 2018 (L). Note: The designations employed and the presentation of the material on this map do not imply the expression of any opinion whatsoever on the part of Research Square concerning the legal status of any country, territory, city or area or of its authorities, or concerning the delimitation of its frontiers or boundaries. This map has been provided by the authors. 


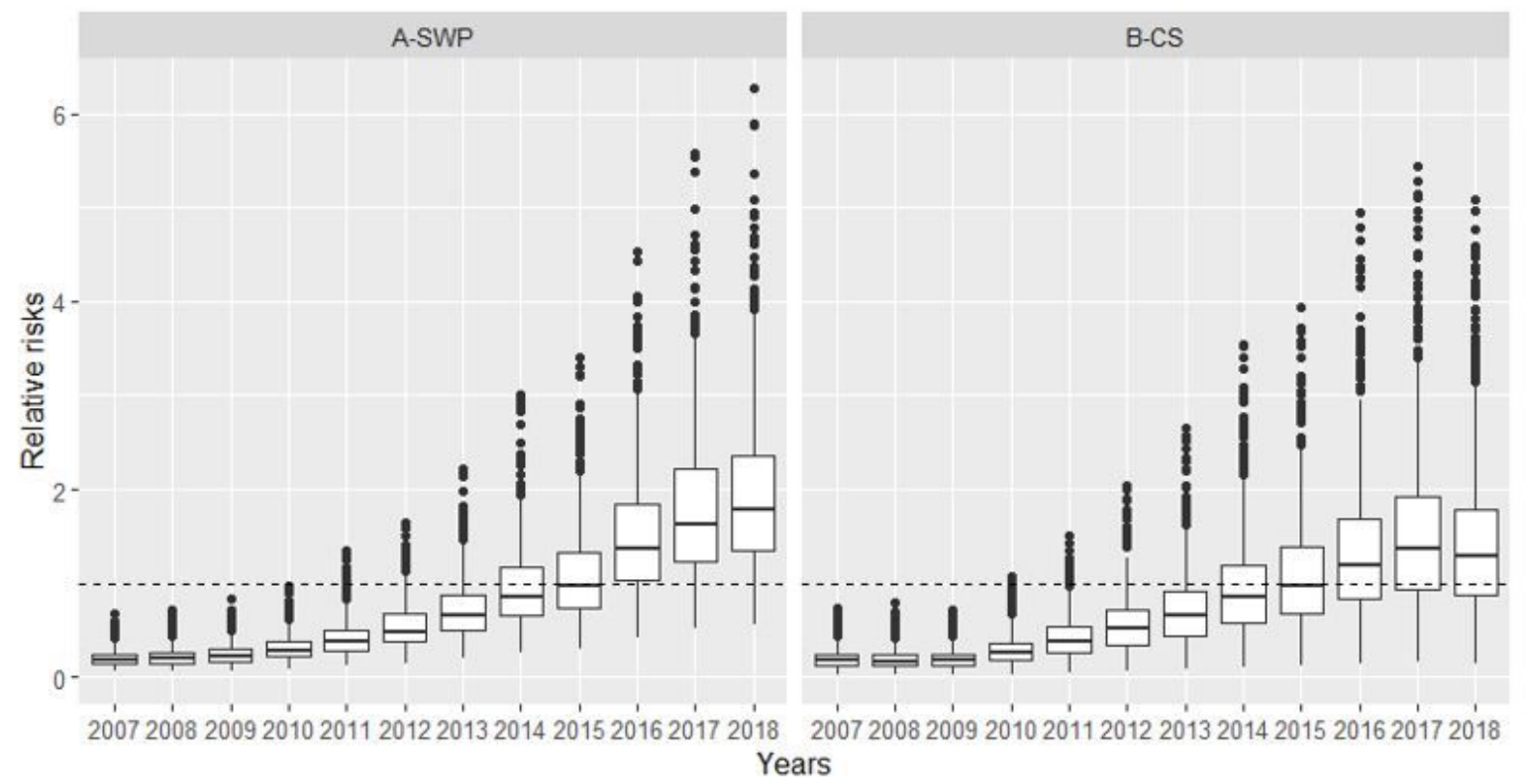

Figure 5

Boxplots with the posterior mean relative risks for syphilis in pregnant women (A-SWP) and congenital syphilis (B-CS) per year, municipalities of the state of São Paulo, 2007 to 2018.

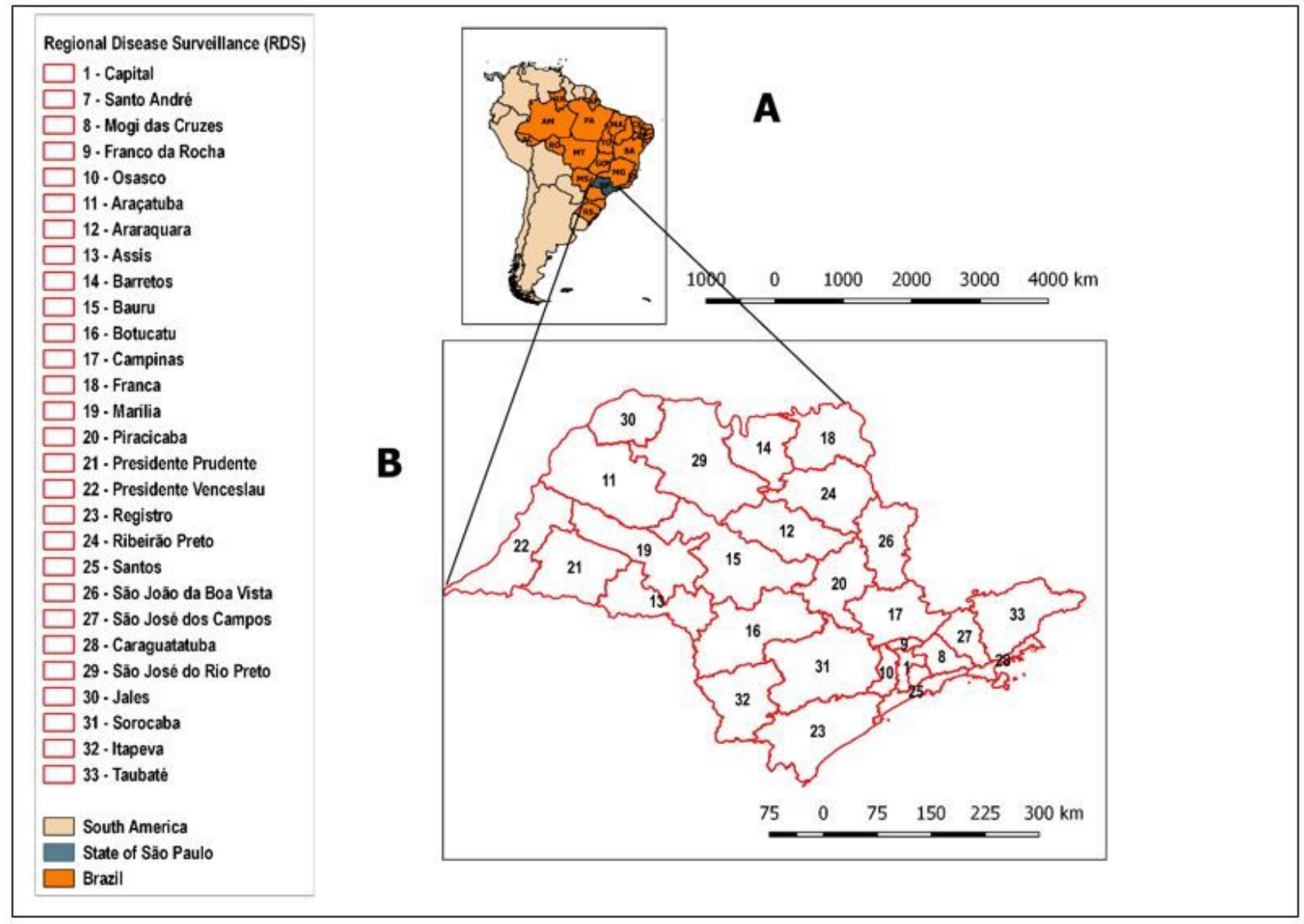

Figure 6 
Geographic Location of the Study area: A) Location of the state of São Paulo in relation to Brazil and South America; B) Location of Regional Disease Surveillance (RDS) in the state of São Paulo Note: The designations employed and the presentation of the material on this map do not imply the expression of any opinion whatsoever on the part of Research Square concerning the legal status of any country, territory, city or area or of its authorities, or concerning the delimitation of its frontiers or boundaries. This map has been provided by the authors.

\section{Supplementary Files}

This is a list of supplementary files associated with this preprint. Click to download.

- SPWCSdatabaseandDictionaryofvariables.xlsx 